\title{
How Emotional Interaction Affects Purchase Intention in Social Commerce: The Role of Perceived Usefulness and Product Type
}

This article was published in the following Dove Press journal: Psychology Research and Behavior Management

\section{Min Wang \\ Lin-Lin Sun \\ Jun-Dong Hou}

School of Economics and Management, China University of Geosciences, Wuhan, People's Republic of China
Correspondence: Jun-Dong Hou

School of Economics and Management,

China University of Geosciences, Wuhan,

People's Republic of China

$\mathrm{Tel}+8618986138760$

Email houjundong@cug.edu.cn
Purpose: On the basis of stimulus-organism-response (SOR) theory, this study extends the work of Lee and Kwon by examining the concept of perceived usefulness as a mediator between emotional interaction (familiarity and intimacy) and purchase intention. The consumer purchase decision model, in which product type plays a moderating role in the linking mechanism, is also explored.

Methods: We proposed a consumer purchase decision model, and empirically examined it by means of an online questionnaire survey. Confirmatory factor analysis and structural equation modeling with bootstrapping estimation were conducted using the data obtained from 269 social commerce users.

Results: Familiarity and intimacy positively affected the users' purchase intention in social commerce. Perceived usefulness mediated the relationship between emotional interaction and purchase intention. Moreover, product type moderated the following relationships: between familiarity and purchase intention, between intimacy and purchase intention, and between perceived usefulness and purchase intention.

Conclusion: The results support this study's hypotheses and SOR theory. Purchase intention could be enhanced by improving emotional interaction and perceived usefulness.

Keywords: social commerce, emotional interaction, perceived usefulness, purchase intention

\section{Introduction}

The technological revolution of Web 2.0 has changed the nature of commerce and led to the emergence of social commerce. ${ }^{1}$ By increasing the consumers' use of social tools, such as WeChat, Twitter, and Facebook, to interact with others, ${ }^{2}$ the social platforms are proving to be an effective way to shop. The major configuration of social commerce lies in its social media usage, interactions of communities and commercial activities. ${ }^{3}$ Unlike e-commerce, social commerce emphasizes emotional interaction among customer, including the sharing of business information and shopping experience. ${ }^{4}$ Through interaction in social commerce, customers can participate in other individuals' shopping experiences to improve their informed purchasing decisions. ${ }^{5}$ Some social commerce activities, such as word-of-mouth marketing, brand product promotion and financing, have been generated on the basis of interpersonal interaction among users. ${ }^{6}$ Consequently, the research regarding interpersonal communication has gradually attracted the attention of scholars. Shen viewed perceived professionality, perceived similarity and perceived 
familiarity as the three factors in interpersonal interaction. ${ }^{7}$ $\mathrm{Ng}$ suggested that familiarity and intimacy are factors of interpersonal interaction from the perspective of social influence theory. ${ }^{8}$ Lee and Kwon ${ }^{9}$ extended the expectation-confirmation model by taking familiarity and intimacy as the two enduring emotion factors to account for the persistence of web service users in manifesting their willingness. Furthermore, different from the traditional online purchase services, social commerce integrates traditional e-commerce, social media, and virtual social resources to conduct business activities, ${ }^{10}$ in which high levels of continuous and effective interaction and stickiness among users are emphasized. In this regard, the emotional interaction (eg, familiarity and intimacy) between customers plays a critical role in social commerce marketing, however, scholars rarely focus on this field. In this study, we take familiarity and intimacy as emotional interaction factors to explore their influence on the purchase intention of social commerce users.

The integration of social elements and e-commerce has not been smooth. In the market report of Booz, ${ }^{11} 73 \%$ of online shoppers do not purchase products on Facebook or other social networking communities, which indicates that users may have different perceptions of the usefulness of information in social business interactions. Moreover, in the technology acceptance model (TAM), attitude plays a decisive role as to whether consumers will use a certain system, and perceived usefulness is one of the key factors affecting attitude. ${ }^{12}$ Therefore, we can infer that perceived usefulness has an important impact on customer interactions and purchase intentions in social commerce. However, the studies are lacking with regard to the role of perceived usefulness in the relationship between emotional interactions and purchase intention in social commerce. Therefore, the focus of this study is to not only examine the purchase intention of social commerce users but also the usefulness that is perceived by users.

In the study of consumer behavior, product type has attracted much attention given its significant impact on the consumers' purchasing decisions. ${ }^{13}$ Consumers obtain different purchase information when they buy different types of products. Furthermore, consumers acquire even more objective information when they buy search products than experience products, indicating that the purchase decision of social commerce consumers may also be affected by product type. ${ }^{14}$ Although many studies regarding product types have been accomplished, ${ }^{15,16}$ only few empirical studies examine the influence of product type and emotional interactions on the consumers' purchasing intention in social commerce. Hence, this study uses the empirical method to examine the moderating effect of product type on the relationship between emotional interactions and purchase intention in social commerce.

The question of whether and how emotional interaction, perceived usefulness and product type affect the social commerce consumers' purchasing intention has not been answered fully in the existing studies. To fill this research gap, we integrate emotional interaction (familiarity and intimacy), perceived usefulness and product type (search products and experience products) into social commerce. Then, drawing on the SOR framework, ${ }^{17}$ this study develops and tests a model to explain the potential psychosocial mechanism involved in the formation of purchasing decision by consumers in social commerce. This study also seeks to explain the formation of purchasing decision by consumers in social commerce from the emotional interaction between users, explore the moderating role of product type in the influence of perceived usefulness on purchasing decision by consumers, and take the perceived usefulness of consumers from the interaction as the bridge of this relationship. In summary, this study examines the following research questions:

(1) Will and how do emotional interactions (familiarity and intimacy) affect the purchase intention of social commerce users?

(2) Will and how does perceived usefulness affect the purchase intention of social commerce users?

(3) Will and how does product type (search products and experience products) affect the purchase intention of social commerce users?

(4) How do emotional interactions, perceived usefulness and product type altogether affect the purchase intention of social commerce users?

\section{Theoretical Framework and Hypotheses}

The definition of social commerce is neither uniform nor definitive in the academia. ${ }^{18}$ Huang and Benyoucef proposed that social commerce refers to e-commerce activities that fully use social media to bring new benefits, ${ }^{19}$ and it is also regarded as a business activity that uses social media and virtual social resources. ${ }^{10}$ In addition, social commerce is considered a special e-commerce with personalized and interactive social relationships. ${ }^{20}$ In this study, social commerce is taken as a business model utilizing the Web 2.0 technology, such as social media, to support the emotional 
interaction of receiving or giving shopping information, experience and feeling. ${ }^{21}$ Social interactions, as a unique characteristic of social commerce, ${ }^{22}$ strengthen the users' social networking relationships and affect their purchase decisions. Social interaction between users can generate social support, improve the relationship, and stimulate the purchase intention. ${ }^{23}$ From the perspective of relationship management, emotional interaction is one of the driving forces of shopping decisions of consumers in social commerce. ${ }^{4}$ For the emotional interaction, social commerce not only can be used to realize the expansion of user groups, but it can also be used to promote the users' shopping experience and improve their purchase intention. ${ }^{24}$ Thus, on the basis of the SOR model as the basic theory, this study selected the emotional interactions between social commerce users as an external stimulus (S), utilized the users' perceived usefulness of the information as an organism $(\mathrm{O})$, and used the purchase intention of social commerce users as the response $(\mathrm{R})$ to explore the internal mechanism.

\section{Relationship Between Emotional Interaction and Purchase Intention}

Social relationships and interactions are the important parts of a social commerce system, ${ }^{25}$ and user participation and interaction are the foundation of social commerce. ${ }^{26}$ Network interaction can be divided into two forms: human-human interaction and human-computer interaction. ${ }^{27}$ In this study, the emotional interaction between users belong to humanhuman interaction, and it mainly reflects the internal emotional elements of interactions to provide emotional support to members. ${ }^{28}$ In explaining the users' long-term intention to use Web services, Lee and Kwon proposed that long-term emotional factors (familiarity and intimacy) play important role, ${ }^{9}$ distinguishing it from the short-term emotional factors (perceived enjoyment and perceived pleasure). In addition, users tend to establish their own circle of friends based on the social platforms, and they form a certain interpersonal attachment and stickiness through flexible and continuous interaction. However, apart from these cognitive factors, the previous studies have rarely paid attention to the emotional factors. ${ }^{29}$ Consequently, this study attempts to explore the emotional interaction between users and divide this interaction into two factors, namely, familiarity and intimacy.

Familiarity is usually defined as “one' s understanding of an entity, often based on previous interactions, experience, and knowledge of the what happened, objects, methods, and time." ${ }^{30,31}$ In this study, familiarity is observed as an affective factor, defining it as a feeling, that is, how much a user feels familiar with other users in social commerce, and the feelings pertain to personal experience. Familiarity also refers to the awareness and understanding of each other based on social interaction. ${ }^{7}$ Moreover, familiarity can reduce uncertainty and post-purchase disharmony and eliminate the doubts of users. ${ }^{32}$ Several researchers of consumer behavior found positive associations between affective familiarity and reuse behavior of customers in the form of good feelings, such as liking. ${ }^{33,34}$ Soerlund proposed that high levels of pre-purchase familiarity is associated with more extreme post-purchase responses in terms of repurchase intention compared with low levels of prepurchase familiarity. ${ }^{35}$ The emotional interaction between users in social commerce allows them to maintain and strengthen contact and familiarity with their partners. Familiarity plays a positive role in the network users' willingness to buy. ${ }^{9}$ Social commerce users with high degree of familiarity can better understand each other's purchasing needs and behavioral habits, hence the deeper exchange of ideas. In this regard, the communication and recommendation of familiar users are usually much more targeted and suitable in simulating purchase intentions. Therefore, we propose the first hypothesis of this study.

H1. Familiarity has a positive impact on purchase intention.

Intimacy is defined as the degree of closeness, which refers to a kind of intimate feeling and emotional connection, including liking and spiritual support. ${ }^{9}$ In this study, intimacy is defined as the emotional connection with relatives and friends, including the degree of interaction and psychological support. According to this definition, intimacy applies to certain types of business relationships. Intimacy has a significant influence on the purchasing, ${ }^{36}$ re-purchase intentions, ${ }^{37}$ continuous intention, ${ }^{9}$ sustainable intention to use, ${ }^{38}$ and number of services to purchase ${ }^{39}$ of clients. Intimacy, a significant feature of emotional interaction in social commerce, can help to ease information asymmetry and improve user experience, and it is known to be positively related to purchase intention. ${ }^{40}$ Close relationships can enhance the willingness of customers to buy products recommended by friends. ${ }^{41}$ In addition, customers with high intimacy, such as close friends and kinfolks, can more easily adopt the product recommendation because of the stickiness and trust emanating from the high level of relationship. A McKinsey report also shows that nearly $50 \%$ of Chinese consumers make their purchasing decisions based on the opinions of relatives or friends. Thus, the second hypothesis is proposed on the basis of the descriptions presented above. 
H2. Intimacy has a positive impact on purchase intention.

\section{Mediating Effect of Perceived Usefulness}

Originally developed by Davis, ${ }^{42}$ TAM is one of the most popular methodologies for analyzing consumer acceptance intentions. Although the relationship between perceived usefulness and intention had originated from the acceptance context, Bhattacherjee argued that a relationship will likely hold true in the purchase context because the human tendency to pursue rewards or benefits do not change. ${ }^{43}$ As consumers in social commerce cannot directly verify environmental features, extrinsic cues, such as detailed product information, have since gained importance. ${ }^{44}$ If consumers perceive the presented information as useful, they consider it in their purchase decision process. ${ }^{45}$ Consequently, many studies have shown that perceived usefulness has a significant positive effect on purchase intention (eg, Cho, ${ }^{46}$ Jamal \& Sharifuddin, ${ }^{47}$ Osburg, ${ }^{48}$ Shina, et $\mathrm{al}^{49}$ Moslehpour, ${ }^{50}$ Zhang, et al ${ }^{51}$ Abdulaziz \& $\mathrm{Kevin}^{52}$ ). According to the studies about perceived usefulness and purchase intention, if users think that the information of goods is useful, then they are likely to use the information and buy the goods that the information refers to. Hence, we propose the third hypothesis.

H3. Perceived usefulness has a positive impact on purchase intention.

With the prevalence of virtuality and information asymmetry in social commerce, consumers are likely to obtain more product and service information by interacting with others. Familiarity, as one of the elements of emotional interaction, has a significant relationship with information sharing in social commerce. ${ }^{53}$ Zhao has developed a humanrelationship theory in the social network context, arguing that familiarity influences the formation of long-term relationships based on the strengthened ties among high-familiarity group members. ${ }^{54}$ The information from the long-term relationships and strong ties has always been regarded creditable and useful. In addition, users in social commerce can obtain much more useful information about goods or services from users who they are familiar with, as social commerce users with high familiarity can better understand each other's likes and habits for a much deeper exchange of ideas. Taking goods or service information from familiar users results in time savings and lowered risk for their online shopping in social commerce. ${ }^{55}$ Moreover, Choi proposed that familiarity has a positive influence on perceived usefulness. ${ }^{56}$ Thus, combined with $\mathrm{H} 3$, we propose the following hypotheses.
H4a. Familiarity has a positive impact on perceived usefulness.

H4. Perceived usefulness mediates the effect of familiarity on the consumers' purchase intention.

Intimacy is defined as feelings of closeness and emotional bonding, and it involves intense liking, moral support, and the ability to tolerate flaws in the significant other. ${ }^{57}$ This concept has been described as a critical variable in emotional interaction and adaptation. ${ }^{58}$ In addition, the degree of intimacy between users has a significant impact on the information effect. ${ }^{59}$ Users are more likely to highly valuable information from others who are intimate in the same social community and more frequently exchange their ideas, as the perception of intimacy may compensate for the ambiguity of the information source's characteristics, presuming that the information is hard to assess in a virtual environment. Therefore, the information retrieved from user-generated sources is often perceived as more useful than the information generated by marketers, ${ }^{60}$ as consumers are connected to users who are similar and intimate to themselves. ${ }^{61}$ In actual scenarios, close relationships among social commerce users would certainly increase the frequency of information exchange. The deeper is the exchange, the more likely are the consumers to accept the views of their friends. Hence, combined with $\mathrm{H} 3$, we propose the following hypotheses:

H5a. Intimacy has a positive impact on perceived usefulness.

H5. Perceived usefulness mediates the effect of intimacy on the consumers' purchase intention.

\section{Moderating Effect of Product Type}

The earliest classification of goods was proposed by Nelson, ${ }^{62}$ who divided goods into two categories - search products and experience products - based on whether individuals could obtain sufficient information about the goods before buying. Search products are those products that can be assessed using externally obtained information. Whereas experience products are those products that must be tested personally by the users. ${ }^{63}$ Many researchers (eg, Jimenez \& Mendoza ${ }^{64}$ Lee \& Shin, ${ }^{16}$ Lu et al ${ }^{65}$ ) have shown that the type of product can affect the consumers' purchase intention. Consumers always believe that online information about search products are more trustworthy than experience products, and they only acquire some subjective information about experience products by interacting with other users. ${ }^{64}$ For the experience goods, the useful information perceived by consumers is usually based on emotional interactions among users (especially familiar or intimate users). Such an 
information can help social commerce customers to make purchase decisions that are more targeted, suitable and efficient. On the basis of the above analysis, we propose the following hypotheses:

H6. Product type moderates the relationship between familiarity and purchase intention, and the positive relationship is stronger when social commerce users purchase an experience product as opposed to a search product.

H7. Product type moderates the relationship between intimacy and purchase intention, and the positive relationship is stronger when social commerce users purchase experience product as opposed to a search product.

Between search goods and experience goods, the method of obtaining useful information differ considerably. For search goods, consumers can obtain objective and comprehensive information from product descriptions and precautions, ${ }^{66}$ they can reasonably evaluate the product needs instead of buying them beforehand owing to a friend's recommendation. In other words, the consumers' purchasing decisions for experience goods are usually biased towards subjective thinking, whereas the purchasing decisions for search goods are often the results of rational thinking. ${ }^{67}$ Compared with search goods, the information about experience goods is more subjective. Therefore, the usefulness perceived by consumers in the emotional interaction with other users in social commerce in the context of experience products has a different impact on the purchasing intention than that of search products. ${ }^{68}$ Therefore, we propose the following hypothesis:

H8. Product type moderates the relationship between perceived usefulness and purchase intention, and the positive relationship is stronger when social commerce users purchase an experience product as opposed to a search product.

\section{Stimulus-Organism-Response Model}

The proposed research model developed following the SOR framework, in which environment stimulus (S) results in emotional response $(\mathrm{O})$ thereby fostering behavioural response (R). Many prior studies (eg, Zafar, et al ${ }^{69}$ Xiang, et $\mathrm{al}^{70} \mathrm{Cao}$, et $\mathrm{al}^{71}$ ) have applied the SOR theory to social commerce. Therefore, SOR seems a rational theory to examine the proposed model.

A stimulus is an environmental cue that incites an individual's behavior intention. ${ }^{72}$ Previous research on social commerce has indicated that the experience of consumers in the context of social commerce is different to that offline, as the consumers have interactions with others. ${ }^{73}$ Once a user interacts with others on social commerce platform, he or she is more likely to become a recurring member in the community, and as time passes, he or she is more likely to become a source of information and emotional interaction. ${ }^{74}$ Thus, emotional interactions (familiarity and intimacy) play a vital role as environmental stimulators that affect the process of users' purchase intention.

The organism reflects internal affective and cognitive state of consumers, ${ }^{75}$ and plays a mediate role between outside environment stimuli and users' behavior response. ${ }^{76}$ Thus, this study focuses on the cognitive state of users in social commerce. Extant literature highlights that in social commerce, perceived usefulness of information play a mediating effect (eg, Osburg, ${ }^{48}$ Moslehpour, ${ }^{50}$ Abdulaziz $\&$ Kevin $^{52}$ ). Therefore, this study took perceived usefulness of users as an organism in social commerce.

Responses represent the final outcomes and decisions of users based on cognitive, affective, or emotional reactions and include approach or avoidance behavior. ${ }^{77}$ In the context of social commerce, the response was the different degree of purchase intention. Consequently, this study concentrated on purchase intention as a response, which is persuaded by familiarity and intimacy through the interceding role of perceived usefulness in social commerce settings. On the basis of SOR theory, the research model and hypotheses are summarized in Figure1.

\section{Methods}

\section{Participants}

The research subjects were consumers who had social business purchase experience, and the questionnaires included 17 observation items that were collected by means of an online survey. To reduce the potential influences of the common method variance (CMV), we presented the questionnaire in random to the participators. ${ }^{78}$ A total of 369 questionnaires were received after six months of data collection. After

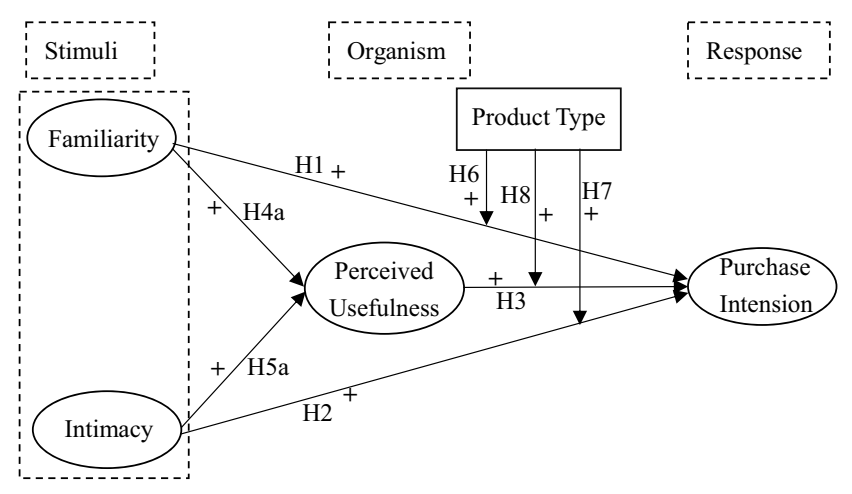

Figure I Research model and hypotheses. 
excluding those questionnaires with no social business purchase experience and the invalid questionnaires, we finally obtained 269 valid questionnaires, with an effective rate of $72.90 \%$. The ratio of the number of valid samples to the number of questionnaire items was greater than $1: 10,{ }^{79}$ and the recovery rate of the valid questionnaires was higher than $70 \%{ }^{80}$ Therefore, the obtained data could be used as research data. Among the valid questionnaires, search goods (mobile phone) and experience goods (cookie) involved 120 and 149 subjects, respectively. In the sampling, $65.43 \%$ of the respondents were women, indicating that female consumers seem to be more enthusiastic about social shopping than male consumers. Then, $86.62 \%$ of the respondents were between the ages of 18 and 37 at the time of data collection, and $89.22 \%$ had a college degree or higher education. Thus, our sampled informants are young and highly educated. In addition, $73.98 \%$ of the consumers-respondents said that they had more than two years of social business purchase experience. In terms of purchase frequency, the participants who purchased more than ten times a month were $13.75 \%$, whereas those respondents who purchased less than three times a month were $33.46 \%$.

\section{Measures}

In view of ensuring the content validity of the scale, the measurement items of the four variables were adapted from the existing maturity scales based on the characteristics of social business. Then, as a means of guaranteeing a more manageable experiment, all variables were measured using a 5-point Likert-type scale ranging from 1 ("strongly disagree") to 5 ("strongly agree"). The items on familiarity and intimacy between customers (Table 1) were adopted from the work of Ng, ${ }^{8}$ Frenzen \& Nakamoto, ${ }^{81}$ and Gilly. ${ }^{82}$ To evaluate the usefulness of products as perceived by customers in social business, we used the variables in the work of Davis ${ }^{42}$ and Park $^{83}$ Then, on the basis of the research of Lee \& Shin ${ }^{16}$ and Zhang, ${ }^{84}$ we obtained the items of purchase intention after applying appropriate modifications. In addition, the

Table I Variable Items

\begin{tabular}{|c|c|c|}
\hline \multicolumn{2}{|l|}{ Items } & Source \\
\hline \multicolumn{2}{|c|}{ Familiarity (FAM) $\alpha=0.875$} & \multirow{4}{*}{$\begin{array}{l}\mathrm{Ng}, 2013 \text {; Frenzen \& Nakamoto, } \\
\qquad 1993\end{array}$} \\
\hline FAMI & I know my friends on social commerce platforms through information exchange. & \\
\hline FAM2 & I know my friends on social commerce platforms by sharing photos. & \\
\hline FAM3 & I interact with friends frequently on the social commerce platform. & \\
\hline \multicolumn{2}{|c|}{ Intimacy (INT) $\alpha=0.892$} & \multirow[t]{5}{*}{ Gilly, 1998} \\
\hline INTI & I will discuss personal topics with friends on social commerce sites. & \\
\hline INT2 & My friends on the social commerce platform are very sincere, and I believe them. & \\
\hline INT3 & I hope to keep a long-term relationship with my friends on the social commerce platform. & \\
\hline INT4 & Friends' recommendations and reviews of goods are a very important to my consumption. & \\
\hline \multicolumn{2}{|c|}{ Perceived usefulness (PU) $\alpha=0.909$} & \multirow[t]{5}{*}{ Davis, 1989; Park, 2009} \\
\hline PUI & The information I get from interactions on social commerce platforms is useful. & \\
\hline PU2 & The interaction on the social commerce platform allows me to better understand purchase goals. & \\
\hline PU3 & The interaction on the social commerce platform enables me to make purchase decisions faster. & \\
\hline PU4 & The information I get from interaction on the social commerce platform is updated timely. & \\
\hline \multicolumn{2}{|c|}{ Purchase intention (PI) $\alpha=0.943$} & \multirow[t]{4}{*}{ Lee and Shin, 2014; Zhang, 1996} \\
\hline PII & $\begin{array}{l}\text { I often want to buy something because of the emotional interaction with others on social commerce } \\
\text { platform. }\end{array}$ & \\
\hline $\mathrm{PI} 2$ & In social commerce, I want strongly to buy the product if it was recommended by my friends. & \\
\hline PI3 & I will buy something because of product recommendations and reviews from my friends. & \\
\hline
\end{tabular}


Cronbach's alpha of variables was set as above 0.8 , to indicate sufficient reliability.

Product type tested by measuring by the consumer's scenario description when they bought the different types of goods in the form of the two products, namely, the experience product and search product. In view of ensuring that the experimental scenario was specific and entailed much better external validity, the study used two parallel experiments to control the representative goods in two types. The study selected eight products (mobile phone, calculator, power bank, USB flash drive, book, movie, skincare product, and cookie) as the representative of the two types. ${ }^{14,44}$ The pre-test experiment involved 35 graduate students. The participants were first required to read the definitions of search goods and experience goods. Then, we used the five-level Likert-type scale to measure the perception towards the pre-purchase qualities of the eight products selected in our study. The following question was asked: "Can you feel the quality of the goods before buying?" The score of mobile phone ( $\mathrm{M}$ mobile phone $=4.06)$ was the highest, whereas the score of cookie (M cookie $=3.31)$ was the lowest, and the difference was significant between the two products $(\mathrm{t}=3.218, \mathrm{p}<$ 0.05). On the basis of the previous definitions of search product and experience product, ${ }^{63,67}$ we selected mobile phone and cookie as the representative of search good and experience good, respectively. Then, two questionnaires were designed on the basis of the two products (ie, mobile phone and cookie). The product type, ie, search product (mobile phone) and experience product (cookie), was used as the moderator.

\section{Common Method Variance}

The survey data were examined for common method bias. As shown in Table 4, the bivariate correlations among the five latent variables do not have extremely high correlations ( $>0.90$ ), suggesting that lack of evidence of common method bias. ${ }^{85}$ In addition, following the studies of Podsakoff et al ${ }^{78}$ and Williams et $\mathrm{al}^{86}$ we included in the structural equation modeling a common method factor whose indicators included all of the principal constructs' indicators. Then, we calculated each indicator's variances, which could be substantively explained by the principal construct and the method. As shown by the results in Table 2, the average substantive variance of the indicators is 0.715 , while the average methodbased variance is 0.051 . The ratio of substantive variance to method variance is approximately 14:1. Furthermore, most of the method factor loadings were not significant. Given the small magnitude and non-significance of the method variance, CMV was unlikely a serious concern in this study.

\section{Results}

\section{Measurement Model}

The conceptual model was tested using AMOS. The relevant indicators and their respective values are shown in Table 3. First, the factor loadings of all items were higher than 0.772, excluding FAM4 (0.731) and INT1 (0.764), suggesting adequate item reliability. The high internal

Table 2 Common Method Bias Analysis

\begin{tabular}{|c|c|c|c|c|c|}
\hline Construct & Indicator & Substantive Factor Loadings $\left(\mathbf{R}_{\mathbf{l}}\right)$ & $\mathbf{R}_{\mathbf{l}}^{2}$ & Method Factor Loadings $\left(\mathbf{R}_{\mathbf{2}}\right)$ & $\mathbf{R}_{\mathbf{2}}{ }^{2}$ \\
\hline \multirow[t]{3}{*}{ FAM } & FAMI & 0.778 & 0.605 & -0.355 & 0.126 \\
\hline & FAM2 & 0.855 & 0.731 & -0.241 & 0.058 \\
\hline & FAM3 & 0.898 & 0.806 & -0.271 & 0.073 \\
\hline \multirow[t]{3}{*}{ INT } & INT2 & 0.782 & 0.612 & -0.026 & 0.001 \\
\hline & INT3 & 0.817 & 0.667 & 0.048 & 0.002 \\
\hline & INT4 & 0.865 & 0.748 & -0.331 & 0.110 \\
\hline \multirow[t]{4}{*}{ PU } & PUI & 0.858 & 0.736 & -0.135 & 0.018 \\
\hline & PU2 & 0.844 & 0.712 & -0.394 & 0.155 \\
\hline & PU3 & 0.832 & 0.692 & -0.236 & 0.056 \\
\hline & PU4 & 0.827 & 0.684 & 0.168 & 0.028 \\
\hline \multirow[t]{3}{*}{ PI } & PII & 0.845 & 0.714 & 0.160 & 0.026 \\
\hline & $\mathrm{PI} 2$ & 0.900 & 0.810 & 0.080 & 0.006 \\
\hline & $\mathrm{PI} 3$ & 0.882 & 0.778 & 0.023 & 0.001 \\
\hline \multicolumn{2}{|l|}{ Average } & & 0.715 & & 0.051 \\
\hline
\end{tabular}


Table 3 Measurement Model Summary

\begin{tabular}{|l|l|l|l|l|l|}
\hline $\begin{array}{l}\text { Research } \\
\text { Construct }\end{array}$ & Items & $\begin{array}{l}\text { Factor } \\
\text { Loading }\end{array}$ & $\mathbf{P}$ & CR & AVE \\
\hline FAM & FAMI & 0.772 & $* * *$ & 0.88 I & 0.712 \\
& FAM2 & 0.844 & $* * *$ & & \\
& FAM3 & 0.910 & $* * *$ & & \\
\hline INT & INT2 & 0.782 & $* * *$ & 0.893 & 0.737 \\
& INT3 & 0.893 & $* * *$ & & \\
\hline PU & INT4 & 0.896 & $* * *$ & & \\
& PUI & 0.871 & $* * *$ & 0.910 & 0.717 \\
& PU2 & 0.858 & $* * *$ & & \\
& PU3 & 0.842 & $* * *$ & & \\
& PU4 & 0.815 & $* * *$ & & \\
\hline PI & PII & 0.913 & $* * *$ & 0.944 & 0.849 \\
& PI2 & 0.928 & $* * *$ & & \\
& PI3 & 0.923 & $* * *$ & & \\
\hline
\end{tabular}

Notes: ***p $<0.001$ (two-tailed); $\mathrm{N}=269$.

Abbreviations: CR, composite reliability; AVE, average variance extracted.

consistency of all of the constructs was confirmed, as the value of the Cronbach alpha was higher than $0.7 .^{87} \mathrm{In}$ addition, the $\mathrm{CR}$ values confirmed the high level of reliability and internal consistency of all of the latent constructs, as the outer loadings of all of the items were higher than the threshold value of 0.6. The AVE values were greater than the threshold value of 0.5 , thus proving the convergent validity of all of the constructs. ${ }^{88}$

As shown in Table 4, all of the shared variance values except for one of them (0.856) were lower than their corresponding AVE values, indicating that the discriminant validity between constructs has not been fully verified. Subsequently, heterotrait-monotrait (HTMT) ratio analysis which is considered to be a superior measure which overcomes the bias of the other techniques was used to verify the discriminant validity. ${ }^{89}$ The obtained HTMT values (Table 4) were statistically significant and smaller than the recommended threshold (HTMT0.90)..$^{90}$ This finding

Table 4 Discriminant Validity

\begin{tabular}{|l|l|l|l|l|}
\hline Research Construct & FAM & INT & PI & PU \\
\hline FAM & & 0.865 & 0.732 & 0.729 \\
\hline INT & 0.856 & & 0.705 & 0.726 \\
\hline PI & 0.718 & 0.704 & & 0.700 \\
\hline PU & 0.728 & 0.714 & 0.701 & \\
\hline
\end{tabular}

Notes: $\mathrm{N}=269$; the elements below the diagonal are the correlations between the construct values, whereas the elements above the diagonal are the HTMT values. suggests that the measurement model can ensure discriminant validity.

\section{Structural Model}

The criteria set used by KIine ${ }^{91}$ was adopted for the normality assessment of the data. The absolute skew and kurtosis values of the observed variables were within the range of 1 , suggesting that these variables were approximately univariate normal. Thus, the index of multivariate kurtosis and its critical ratio ${ }^{92}$ should be considered. Bentler suggested that, in practice, the c.r. values $>5.00$ are indicative of non-normally distributed data. ${ }^{93}$ In this research, the c.r. value of 39.934 (see Appendix A) corresponded to non-normality in the sample.

Non-normality leads to an overestimation of the chisquared statistic (the degree of discrepancy between the model-implied and sample-derived covariance matrices), potentially leading to a false rejection of the model as whole. Subsequently, the underestimation of the standard errors of the parameter estimates can lead to inflated statistics, hence the possibly erroneous attributions of significance of specific relationships in the model. One approach of handling multivariate non-normal data is to use a procedure known as "bootstrapping". ${ }^{94,95}$ As such, we used the bootstrap technique to correct the model fit. As shown by the details of the corrected structural model in Table 5, the hypothesized model fits well the data $\left(\chi^{2}=87.53, \mathrm{df}=59\right.$,

Table 5 Model Fit Indices of Model

\begin{tabular}{|l|l|l|l|}
\hline Fit Indices & $\begin{array}{l}\text { Model } \\
\text { Value }\end{array}$ & $\begin{array}{l}\text { Reference } \\
\text { Value }\end{array}$ & $\begin{array}{l}\text { Overall } \\
\text { Model } \\
\text { Fit }\end{array}$ \\
\hline Bollen-Stine $\chi 2$ & 87.53 & $\begin{array}{l}\text { The lesser. } \\
\text { the better }\end{array}$ & Yes \\
\hline DF & 59.00 & $\begin{array}{l}\text { The larger, } \\
\text { the better }\end{array}$ & Yes \\
\hline Normed Chi-aqr $(\chi 2 / D F)$ & 1.48 & $(\mathrm{I}, 3)$ & Yes \\
\hline Goodness of Fit Index (GFI) & 0.97 & $>0.9$ & Yes \\
\hline $\begin{array}{l}\text { Adjusted Goodness of Fit } \\
\text { Index (AGFI) }\end{array}$ & 0.94 & $>0.9$ & Yes \\
\hline $\begin{array}{l}\text { Root Mean Squared Error of } \\
\text { Approximation (RMSEA) }\end{array}$ & 0.04 & $<0.08$ & Yes \\
\hline Tucker Lewis Index (TLI) & 0.99 & $>0.9$ & Yes \\
\hline Comparative Fit Index (CFI) & 0.99 & $>0.9$ & Yes \\
\hline
\end{tabular}

Notes: $\mathrm{N}=269$; estimation of 5000 bootstrap sample. 
$\chi^{2} / \mathrm{df}=1.48, \mathrm{GFI}=0.97, \mathrm{AGFI}=0.94, \mathrm{TLI}=0.99, \mathrm{CFI}=$ 0.99 , IFI $=0.99$, RMSEA $=0.04$ ).

Figure 2 presents the results of the AMOS analysis of the structural model. As shown by the correlation coefficients in Table 6, familiarity is positively and significantly related to purchasing intention $(r=0.465, p=0.001)$, and intimacy is also positively and significantly related to purchasing intention $(\mathrm{r}=$ $0.449, \mathrm{p}<0.001)$. In addition, the results of the direct effect of familiarity on purchase intention (standardized direct effect $=$ $0.299, p=0.041$; Table 7) and the direct effect of intimacy on purchase intention (standardized direct effect $=0.305, \mathrm{p}=$ 0.018 ) are both statistically significant. Thus, $\mathrm{H} 1$ and $\mathrm{H} 2$ are supported.

As similarly shown by the correlation coefficients in Table 6 , familiarity is positively and significantly related to perceived usefulness $(r=0.500, p<0.001)$, intimacy is positively and significantly related to perceived usefulness $(r=0.432, p<0.001)$, and perceived usefulness is positively and significantly related to perceived usefulness $(r=0.613$, $\mathrm{p}<0.001$ ). Therefore, H4a, H5a and H3 are supported.

The results pertaining to $\mathrm{H} 4$ and $\mathrm{H} 5$ are shown in Table 7. The direct effect of familiarity on perceived usefulness (standardized direct effect $=0.500, p<0.001$ ), the direct effect of intimacy on perceived usefulness (standardized direct effect = $0.432, p<0.001$ ), and the direct effect of perceived usefulness on purchase intention (standardized direct effect $=0.332$, $\mathrm{p}=0.030$ ) are all statistically significant. Therefore, the mediation of perceived usefulness in our model is supported. To investigate the indirect effects of the dependent variable through the mediators, we performed percentile bootstrapping and bias-corrected percentile bootstrapping at the $95 \%$ confidence interval with 5000 bootstrap samples. ${ }^{96}$ We followed the suggestions of Preacher and Hayes ${ }^{97}$ and calculated the confidence intervals of the lower and upper bounds to test whether the indirect effects were significant. The bootstrap test results shown in Table 7, confirm the existence of a positive and significant mediating effect of perceived usefulness between intimacy and purchase intention (standardized indirect effect $=$ $0.143, \mathrm{p}=0.021,95 \% \mathrm{CI}=[0.025,0.271])$ and a positive and significant mediating effect of perceived usefulness between familiarity and purchase intention (standardized indirect effect $=0.166, p=0.007, \mathrm{CI}=[0.046,0.279])$. Therefore, $\mathrm{H} 4$ and H5 can be verified.

In exploring the moderating effects of product type, multigroup structural modeling ${ }^{98}$ was conducted to examine H6, $\mathrm{H} 7$ and H8. First, we set as equal the path coefficients from familiarity to purchase intention, and then we estimated freely the other path coefficients for both of the search product (mobile phone) and experience product (cookie) groups. Therefore, the chi-square difference between this

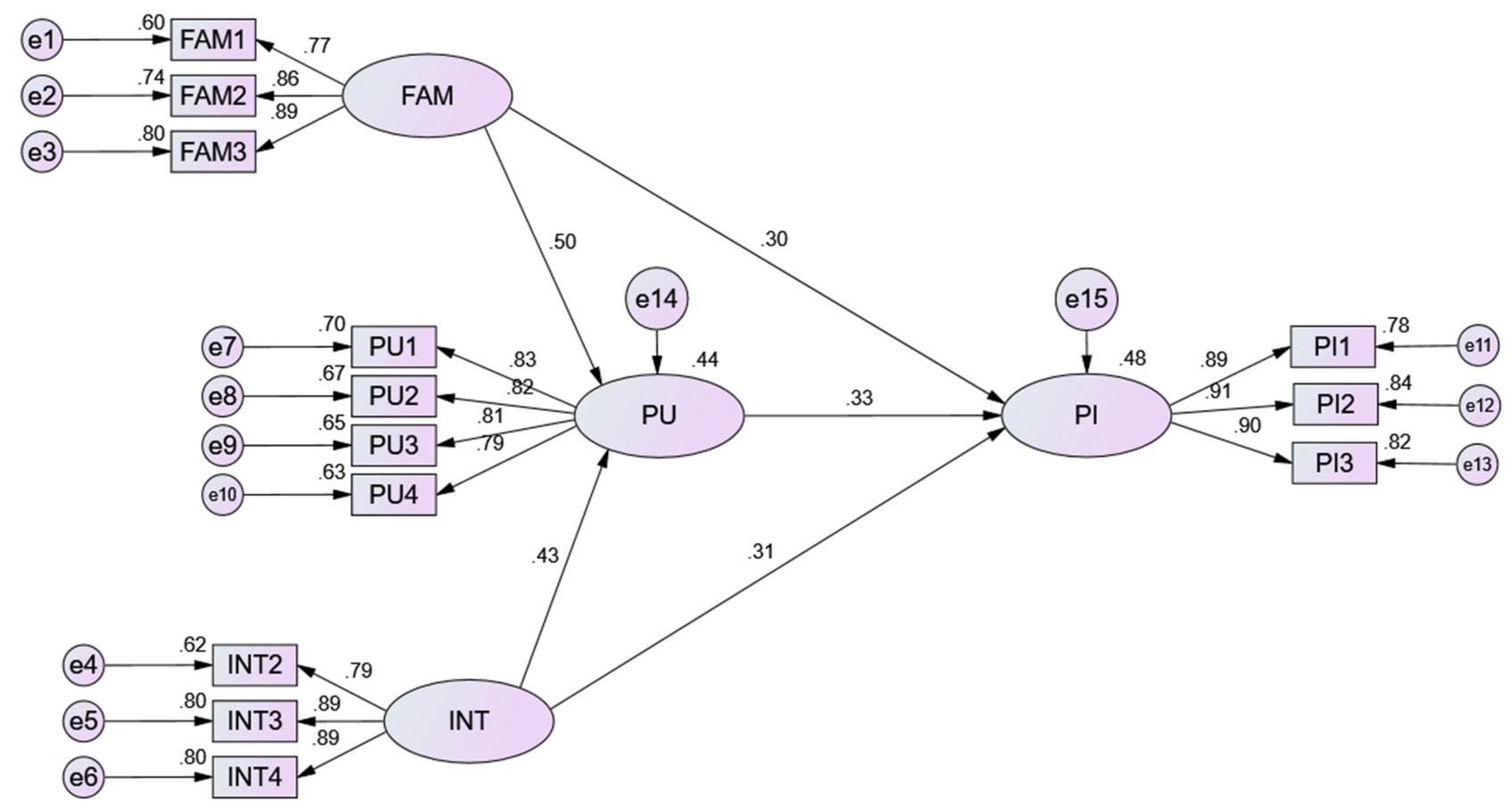

Figure 2 Structural model.

Abbreviations: FAM, familiarity; INT, intimacy; PU, perceived usefulness; PI, purchase intention. 
Table 6 Descriptive Statistics and Correlations of Variables

\begin{tabular}{|l|l|l|l|l|l|l|}
\hline Research Construct & Mean & SD & FAM & INT & PU \\
\hline FAM & 3.098 & 0.965 & $(0.875)$ & & \\
\hline INT & 2.960 & 1.015 & 0.000 & $(0.892)$ & & \\
\hline PU & 3.515 & 0.804 & $0.500^{* * *}$ & $0.432^{* * *}$ & $(0.909)$ & $0.613^{* * *}$ \\
\hline PI & 3.140 & 1.081 & $0.465^{* * *}$ & $0.449 * * *$ & $(0.943)$ \\
\hline
\end{tabular}

Notes: ***p < 0.001 (two-tailed); $\mathrm{N}=269$; figures in parentheses are Cronbach's alpha values.

Abbreviation: SD, standard deviation.

Table 7 Standardized Direct, Indirect, and Total Effects of the Hypothesized Model

\begin{tabular}{|c|c|c|c|c|c|c|}
\hline \multirow[t]{3}{*}{ Research Construct } & \multirow[t]{3}{*}{ Point Estimate (c) } & \multirow{2}{*}{\multicolumn{2}{|c|}{ Product of Coefficients }} & \multicolumn{3}{|c|}{ Bootstrapping } \\
\hline & & & & \multicolumn{2}{|c|}{ Percentile $95 \% \mathrm{Cl}$} & \multirow[t]{2}{*}{ Two-Tailed Significance } \\
\hline & & SE & $\mathbf{Z}$ & Lower & Upper & \\
\hline $\mathrm{FAM} \rightarrow \mathrm{PI}$ & 0.299 & 0.146 & 2.048 & 0.034 & 0.602 & $0.04 I(* *)$ \\
\hline $\mathrm{INT} \rightarrow \mathrm{PI}$ & 0.305 & 0.129 & 2.364 & 0.053 & 0.554 & $0.018(* *)$ \\
\hline $\mathrm{PU} \rightarrow \mathrm{PI}$ & 0.332 & 0.111 & 2.991 & 0.090 & 0.522 & $0.003(* *)$ \\
\hline $\mathrm{FAM} \rightarrow \mathrm{PU}$ & 0.500 & 0.125 & 4.000 & 0.262 & 0.736 & $00.000(* * *)$ \\
\hline $\mathrm{INT} \rightarrow \mathrm{PU}$ & 0.432 & 0.122 & 3.541 & 0.162 & 0.631 & $00.000(* * *)$ \\
\hline $\mathrm{FAM} \rightarrow \mathrm{PI}$ & 0.166 & 0.062 & 2.677 & 0.046 & 0.297 & $0.007(* *)$ \\
\hline INT $\rightarrow$ PI & 0.143 & 0.062 & 2.306 & 0.025 & 0.271 & $\left.0.021{ }^{* *}\right)$ \\
\hline $\mathrm{FAM} \rightarrow \mathrm{PI}$ & 0.465 & 0.125 & 3.720 & 0.214 & 0.691 & $0.000(* * *)$ \\
\hline $\mathrm{INT} \rightarrow \mathrm{PI}$ & 0.449 & 0.127 & 3.535 & 0.177 & 0.665 & $00.000(* * *)$ \\
\hline $\mathrm{PU} \rightarrow \mathrm{PI}$ & 0.332 & 0.111 & 2.991 & 0.090 & 0.522 & $0.003(* *)$ \\
\hline $\mathrm{FAM} \rightarrow \mathrm{PU}$ & 0.500 & 0.125 & 4.000 & 0.262 & 0.736 & $0.000(* * *)$ \\
\hline $\mathrm{INT} \rightarrow \mathrm{PU}$ & 0.432 & 0.122 & $3.54 I$ & 0.162 & 0.631 & $\left.0.000{ }^{* *}\right)$ \\
\hline
\end{tabular}

Notes: $* * p<0.005 ; * * * p<0.001$ (two-tailed).

Abbreviation: SE, standard error.

constrained model and the unconstrained ones could be used to examine H6. As shown in Table 8 , the chi-square difference is significant $\left(\Delta \chi_{(1)}^{2}=17.540, p<0.001\right)$, and the coefficients estimated from familiarity to purchase intention are 0.255 in the search product (mobile phone) group and 0.257 in the experience product (cookie) group. As expected, the positive relationship between familiarity and purchase intention is stronger when social commerce users buy an experience product as opposed to a search product, thus supporting H6. Second, we set as equal the path coefficient from intimacy to purchase intention, and then the other relationships in the model were estimated freely between the search product (mobile phone) and experience product (cookie) groups. As shown in Table 8, the chi-square difference is significant $\left(\Delta \chi_{(3)}^{2}=1.945, \mathrm{p}=0.163\right)$ between the constrained and unconstrained models, and the coefficients estimated from intimacy to purchase intention are $0.260(\mathrm{p}=$ 0.017 ) in the search product (mobile phone) group and 0.318 $(p=0.008)$ in the experience product (cookie) group. The finding indicates that the positive relationship between intimacy and purchase intention is stronger when social commerce users buy an experience product as opposed to a search product, therefore supporting H7. Finally, we set as equal the path coefficients from perceived usefulness to purchase intention, leaving the other relationships to be freely estimated in both product type groups. The results shown in 
Table 8 Invariance Test of the Two-Group Structural Model and Testing the Moderating Effects

\begin{tabular}{|c|c|c|c|c|c|c|c|}
\hline & \multicolumn{2}{|c|}{ Search Group $(N=120)$} & \multicolumn{2}{|c|}{ Experience Group $(N=149)$} & \multirow{2}{*}{$\begin{array}{l}\text { Unconstrained } \\
\text { Model Chi-Square } \\
(\mathrm{df}=120)\end{array}$} & \multirow{2}{*}{$\begin{array}{l}\text { Constrained } \\
\text { Model Chi-Square } \\
(\mathrm{df}=12 \mathrm{I})\end{array}$} & \multirow{2}{*}{$\begin{array}{l}\Delta \chi^{2} \\
(\Delta d f=I)\end{array}$} \\
\hline & $\begin{array}{l}\text { Standardized } \\
\text { Coefficients }\end{array}$ & Z-Value & $\begin{array}{l}\text { Standardized } \\
\text { Coefficients }\end{array}$ & Z-Value & & & \\
\hline $\mathrm{FAM} \rightarrow \mathrm{PI}$ & 0.255 & 1.393 & 0.257 & 1.736 & 616.104 & 633.644 & $17.540 * * *$ \\
\hline $\mathrm{INT} \rightarrow \mathrm{PI}$ & 0.260 & $2.385^{*}$ & 0.318 & $2.650^{*}$ & 616.104 & 618.049 & 1.945 \\
\hline $\mathrm{PU} \rightarrow \mathrm{PI}$ & 0.339 & $4.291 *$ & 0.525 & $3.646 *$ & 616.104 & 623.946 & $7.842 * * *$ \\
\hline
\end{tabular}

Notes: Standardized estimation of 5000 bootstrap samples; ${ }_{p} p<0.05 ; *^{*} *_{p}<0.001$ (two-tailed).

Table 8 reveal that the chi-square difference is significant $\left(\Delta \chi_{(5)}^{2}=7.842, \mathrm{p}=0.005\right)$ between the constrained and unconstrained models, and the coefficients estimated from perceived usefulness to purchase intention are 0.339 ( $\mathrm{p}<$ 0.001 ) in the search product (mobile phone) group and 0.525 $(\mathrm{p}<0.001)$ in the experience product (cookie) group. As expected, the positive relationship between perceived usefulness and purchase intention is stronger when social commerce users buy an experience product as opposed to a search product. Thus, H8 is supported.

\section{Discussion}

The study has verified that familiarity and intimacy positively affect purchase intention. Familiarity and intimacy are two important antecedents that influence the consumers' purchase intention in social commerce. As an integral part of the network-based transaction method, the purchase intentions of social commerce users are often disrupted by large amounts of redundant information. Such sources of information have become the focus of consumer attention as a means of identifying the reliability of information and obtaining much more useful information. Emotional interactions by means of sharing purchasing activities and considering consumer experience can increase the familiarity and intimacy between social commerce users, and this approach further affects purchase intention in relation to the use of credible information. In general, information from friends with high intimacy often means high credibility. Consequently, consumers are more willing to accept the information, and users with high familiarity have more consistent views and valuation of the products. Therefore, the purchase intention of social commerce users is often influenced by someone who has high intimacy or high familiarity with them. When making purchase decisions over social commerce platforms, such as Pinterest (https://www.pinterest.com/) and Xiaohongshu (https://www.xiaohongshu.com/), consumers tend to focus on the product information provided by familiar users and close friends. Thus, highly familiar users or highly intimate friends often become an important reference group when making purchasing decisions.

On the basis of SOR theory, this study extends the work of Lee and Kwon ${ }^{9}$ by examining perceived usefulness as a mediator between emotional interaction (familiarity and intimacy) and purchase intention. Although the users' purchase intentions are directly affected by familiarity and intimacy, as rational consumers, they still judge the reliability or usefulness of the information provided by other users. In social commerce platforms, the emotional interaction between users is one of the key reasons for consumers to judge the quality of an obtained information. In the case of asymmetric information, consumers tend to trust the interactive information shared by users they are more familiar or intimate with, this tendency can help users perceive the usefulness of an information more easer. When users perceive the useful information as sufficient, they can reduce the expected risk that is associated with the inaccessibility of physical goods, thereby prompting the generation of their purchase intention.

Product types can be adjusted to handle the effect of perceived usefulness on purchase intention. However, for purchase scenarios involving different product types, the purchase information obtained by consumers differs, and the perceived usefulness of information also varies. Compared with consumers with low perceived usefulness, consumers with high perceived usefulness are more likely to generate purchase intentions. In social commerce, the consumers of experience goods need to learn from the buying feelings and user experiences shared by other consumers. In other words, the impact of perceived usefulness on the consumers' purchase intention of experience products is more obvious than those of any other types of goods. 


\section{Implications}

This study offers four contributions to the field of social commerce. First, we have developed a model that integrates the theory of emotional interaction and purchase intention. The results not only support the findings of prior studies in which emotional interaction significantly affects purchase intention, but the conclusions can also be applied to a new scenario-social commerce. Second, our findings have revealed that strengthening the social commerce users' familiarity or intimacy can enhance their perceived usefulness with regard to purchase intention. Thus, social commerce platforms should find ways to enhance the customers' emotional interaction to improve their purchase intention by means of the mediated effect of perceived usefulness. Third, our study has extended the work of Lee and Kwon ${ }^{9}$ by examining perceived usefulness as a mediator between emotional interaction and purchase intention. Our results also indicate that firms can enhance the social commerce users' purchase intention by increasing familiarity via perceived usefulness in favor of intimacy. In addition, companies can enhance the social commerce users' purchase intention by increasing the products' usefulness, which can be perceived by means of emotional interaction. Finally, this empirical research has expanded the work of $\mathrm{Xie}^{66}$ by examining product type as a moderator of the relationships between emotional interaction (familiarity and intimacy) and purchase intention, and between perceived usefulness and purchase intention. The results further reveal a stronger relationship between emotional interaction and purchase intention when buying experience products as opposed to buying search products and a stronger relationship between perceived usefulness and purchase intention. These results also support the view that social commerce users are more easily affected by emotional interaction when buying experience products (mobile phones) as opposed to buying search products (cookies).

The results offer insights into the management practice of social commerce. First, the results suggest that enterprises or platforms should pay more attention to the effects of emotional interactions of users. Managers should use this relationship among social commerce users to analyze their connection nodes, achieve precise marketing, reduce marketing cost, expand marketing scope, and increase user purchases. Second, as familiarity and intimacy can promote the purchase intentions of users, managers of social business platforms should actively create an atmosphere of convenience, such as offering reward mechanisms, to stimulate and enhance emotional interaction among social commerce users. Finally, the positive relationships between emotional interaction (familiarity and intimacy) and purchase intention and between perceived usefulness and purchase intention are further strengthened when social commerce users purchase an experience product as opposed to a search product. Thus, for experience products, such as cookies, movies and skincare products, merchants should pay more attention to enhancing the emotional interaction among social commerce users.

\section{Limitations}

Although this research offers certain theoretical contributions and practical implications, several limitations have been observed. First, the study used online survey to collect experimental data. Controlling the answering environment is impossible, and it may even be subject to deviations due to the interference of the experimental subjects' environment and other factors. In the future, researchers may rely on social commerce platforms to collect objective data by means of web crawlers or use field-scenario experiments or multi-experiment methods to alleviate the validation bias of the data.

Second, although this study has considered the moderating effect of product type, the purchasing propensity of consumers may have differed on the basis of gender. Female consumers may be more sensitive to information. Subsequent research can test the consumer's gender differences for the effect of perceived usefulness and purchasing relationships.

Finally, the study found that the emotional interaction factors (familiarity and intimacy) of users in social commerce platforms have a significant impact on perceived usefulness, but the variance interpretation rate is $49 \%$, indicating that other factors may have been ignored. Future research may consider such factors as time of information dissemination, perceived risk, social support, or the combination of technology and social attributes.

\section{Conclusion}

Purchase intention in social commerce is affected by emotional interaction (familiarity and intimacy) and perceived usefulness. The positive relationships between emotional interaction and purchase intention and between perceived usefulness and purchase intention are stronger when social commerce users purchase experience products instead of search products. Thus, this study suggests that strategies 
aimed at enhancing emotional interaction and perceived usefulness should be developed to enhance the purchase intention of social commerce users.

\section{Ethics Approval and Informed Consent}

This study was reviewed and approved by the China University of Geosciences Ethics Committee, and all methods were performed in accordance with government regulations, laboratory policies, and the 1964 Helsinki Declaration. All subjects gave their informed consent for inclusion before they participated in the study. The involvement of participants younger than 18 was approved by the Ethics Committee, who provided informed consent on their behalf.

\section{Funding}

This research was supported in part by the National Natural Science Foundation of China (Grant Nos. 71874163 and 71572185$)$.

\section{Disclosure}

No conflict of interest is declared by the authors of this work.

\section{References}

1. Alalwan AA, Algharabat RS, Baabd Lee AM, et al. Examining the impact of social commerce dimensions on customers' value cocreation: the mediating effect of social trust. $J$ Consum Behav. 2019;18:431-446. doi:10.1002/cb.1782

2. Gruzd A, Wellman B, Takhteyev Y. Imagining Twitter as an imagined community. Am Behav Sci. 2011;55(10):1294-1318. doi:10.1177/ 0002764211409378

3. Liang TP, Turban E. Introduction to the special issue social commerce: a research framework for social commerce. Int $J$ Electron Commer 2011;16(2):5-13. doi:10.2753/JEC1086-4415160201

4. Tang J, Zhang B. User willingness to purchase applications on mobile intelligent devices: evidence from app store. Asia Pac J Market Logist. 2019;6:411-432. doi:10.1108/APJML-06-2019-0411

5. Wang YC, Yu CH. Social interaction-based consumer decision-making model in social commerce: the role of word of mouth and observational learning. Int J Inf Manage. 2017;37(3):179-189. doi:10.1016/j. ijinfomgt.2015.11.005

6. Jin C. The perspective of a revised TRAM on social capital building: the case of Facebook usage. Inf Manage. 2013;50(4):162-168. doi:10.1016/j.im.2013.03.002

7. Shen YC, Huang CY, Chu CH, Liao HC. Virtual community loyalty: an interpersonal interaction perspective. Int $J$ Electron Commer. 2010;15(1):49-74. doi:10.2753/JEC1086-4415150102

8. Ng CSP. Intention to purchase on social commerce websites across cultures: a cross-regional study. Inf Manage. 2013;50(8):609-620. doi:10.1016/j.im.2013.08.002

9. Lee Y, Kwon O. Intimacy, familiarity and continuance intention: an extended expectation-confirmation model in web-based services. Electron Commer Res Appl. 2011;10(3):342-357. doi:10.1016/j. elerap. 2010.11 .00
10. Curty RG, Zhang P. Social commerce: looking back and forward. Proceed Am Soc Inf Sci Technol. 2012;48(1):1-10.

11. Anderson M, Sims J, Price J, et al. Turning Like to Buy Social Media Emerges as a Commerce Channel. Chicago: Booz \& Company Incorporated; 2011.

12. Wan LY, Zhang JW Research on the influence of friend circle advertisement on consumers' purchase intention-based on technology acceptance model theory. 2019 International Conference on Modern Education and Economic Management 2019.

13. Xu J, Schwarz N. Do we really need a reason to indulge? J Mark Res. 2009;46(1):25-36. doi:10.1509/jmkr.46.1.25

14. Hsu CL, Yu LC, Chang KC. Exploring the effects of online customer reviews, regulatory focus, and product type on purchase intention: perceived justice as a moderator. Comput Hum Behav. 2017;69:335-346. doi:10.1016/j.chb.2016.12.056

15. Danny W, Scott DS, Varun G. Can online product reviews be more helpful? Examining characteristics of information content by product type. Decis Support Syst. 2015;79:12-23. doi:10.1016/j.dss.2015.07.009

16. Lee EJ, Shin SY. When do consumers buy online product reviews: effects of review quality, product type, and reviewer's photo. Comput Hum Behav. 2014;31:356-366. doi:10.1016/j.chb.2013.10.050

17. Xin L, Song YX. Research on the influence of social business platform on the value co-creation behavior of users. J Commer Econ. 2019;24:59-63.

18. Liu HF, Chu HL, Huang Q, Chen XY. Enhancing the flow experience of consumers in China through interpersonal interaction in social commerce. Comput Hum Behav. 2016;58:306-314. doi:10.1016/j. chb.2016.01.012CO

19. Huang Z, Benyoucef M. From e-commerce to social commerce: a close look at design features. Electronic Commer Res Appli. 2013;12(3):246-259. doi:10.1016/j.elerap.2012.12.003

20. Rad A, Benyoucef M. A model for understanding social commerce. J Inf Syst Appl Res. 2011;4(2):63-73.

21. Zhang H, Lu Y, Gupta S, Zhao L. What motivates customers to participate in social commerce? The impact of technological environments and virtual customer experiences. Inf Manage. 2014;51 (8):1017-1030. doi:10.1016/j.im.2014.07.005

22. Busalim AH, Hussin ARC. Understanding social commerce: a systematic literature review and directions for further research. Int J Inf Manage. 2016;36(6):1075-1088. doi:10.1016/j.ijinfomgt.2016.06.005

23. Hajli MN. Social commerce for innovation. Int J Innov Manage. 2014;18(4):1-24. doi:10.1142/S1363919614500248

24. Fu SH, Xu Y, Yan Q. Enhancing the parasocial interaction relationship between consumers throughs similarity effects in the context of social commerce evidence from social commerce platforms in China. $J \quad$ Strategic Market. 2019;27(2):100-118. doi:10.1080/ 0965254X.2017.1384045

25. Esmaeili L, Golpayegani AH. Conformance checking of the activity network with the social relationships structure in the context of social commerce. J Theor Appl Electron Commer Res. 2019;11:93-121. doi:10.4067/S0718-18762020000200107

26. Wang HW, Meng Y, Wang W. The role of perceived interactivity in virtual communities: building trust and increasing stickiness. Connect Sci. 2013;19(6):1261-1271. doi:10.4067/S0718-18762020000200107

27. Hoffman DL, Novak TP. Marketing in hypermedia mediated environments: conceptual foundations. $J$ Mark. 1997;60(3):50-68. doi: $10.1177 / 002224299606000304$

28. Brito PQ, Torres S, Fernandes J. What kind of emotions do emoticons communicate? Asia Pac J Market Logist. 2019;3:28-59.

29. Ren XM. Research on the relationship between user interaction, emotional attachment and user stickiness-analysis based on attachment decision theory and emotional mechanism [in Chinese]. J Yanshan Univ. 2018;19(3):88-96.

30. Gefen D. E-commerce: the role of familiarity and trust. Omega-Int $J$ Manage Sci. 2000;28(6):725-737. doi:10.1016/S0305-0483(00) 00021-9 
31. Komiak XS, Benbasat I. The effects of personalization and familiarity on trust and adoption of recommendation agents. MIS Q. 2006;30 (4):941-960. doi:10.2307/25148760

32. Hinds PJ, Carley KM, Krackhardt D, Wholey D. Choosing work group members: balancing similarity, competence, and familiarity. Organ Behav Hum Decis Process. 2000;81(2):226-251. doi:10.1006/obhd.1999.2875

33. Colombo RA, Morrison DG. A brand switching model with implications for marketing strategies. Mark Sci. 1989;8:89-99. doi:10.1287/ mksc.8.1.89

34. Raj SP. Striking a balance between brand 'popularity' and brand loyalty. J Mark. 1985;49:53-59.

35. Soerlund M. Customer familiarity and its effects on satisfaction and behavioral intentions. Psychol Mark. 2002;19(10):861-880. doi: $10.1002 /$ mar. 10041

36. Grayson K, Ambler T. The dark side of long-term relationships in marketing services. J Mark Res. 1999;36(1):132-141. doi:10.2307/ 3151921

37. Brock JKU, Zhou JY. Customer intimacy. J Bus Ind Mark. 2012;27 (5):370-383. doi: $10.1108 / 08858621211236043$

38. Lee KH, Ullah S. Customers' attitude toward Islamic banking in Pakistan. Int J Islamic Middle Eastern Finance Manage. 2011;4 (2):131-145. doi:10.1108/17538391111144524

39. Verhoef PC, Francis PH, Hoekstra JC. The effect of relational constructs on customer referrals and number of services purchased from multiservice provider: does age of relationship matter? J Acad Mark Sci. 2002;30(3):202-212. doi:10.1177/0092070302303002

40. Horng SM, Wu CL. How behaviors on social network sites and online social capital influence social commerce intentions. Inf Manage. 2020;57(4):1-13. doi:10.1016/j.im.2019.103176

41. Park MS, Shin JK, Ju Y. The effect of online social network characteristics on consumer purchasing intention of social deals. Global Econ Rev. 2014;43(1):25-41. doi:10.1080/1226508X.2014.884047

42. Davis FD. Perceived usefulness, perceived ease of use and user acceptance of information technology. MIS Q. 1989;13:319-340. doi: $10.2307 / 249008$

43. Bhattacherjee A. Understanding information systems continuance: an expectation-confirmation model. MIS Q. 2001;25(3):351-370. doi: $10.2307 / 3250921$

44. Kirchhoff S. Green business and blue angels: a model of voluntary overcompliance with asymmetric information. Environ Resour Econo. 2000;15(4):403-420. doi:10.1023/A:1008303614250

45. Cohen M, Vandenbergh M. The potential role of carbon labeling in a green economy. Energy Econ. 2012;34(1):53-63. doi:10.1016/j. eneco.2012.08.032

46. Cho YC. Exploring factors that affect usefulness, ease of use, trust, and purchase intention in the online environment. Int J Manage Inf Syst. 2015;19(1):21-35.

47. Jamal A, Sharifuddin J. Perceived value and perceived usefulness of halal labeling: the role of religion and culture. J Bus Res. 2015;68 (5):933-941. doi:10.1016/j.jbusres.2014.09.020

48. Osburg VS, Yoganathan V, Brueckner S, Toporowski W. How detailed product information strengthens eco-friendly consumption. Manage Decis. 2020;58(6):108-1099. doi:10.1016/j. jbusres.2014.09.020

49. Shina J, Parkb Y, Lee D. Who will be smart home users? An analysis of adoption and diffusion of smart homes. Technol Forecast Soc Change. 2018;134:246-253. doi:10.1016/j.techfore.2018.06.029

50. Moslehpour M, Pham VK, Wong WK, Bilgiçli I. e-Purchase intention of Taiwanese consumers: sustainable mediation of perceived usefulness and perceived ease of use. Sustainability. 2018;10(1):234-255. doi:10.3390/su10010234

51. Zhang TT, Wang WC, Cao L, Wang Y. The role of virtual try-on technology in online purchase decision from consumers' aspect. Internet Res. 2019;29(3):529-551. doi:10.1108/IntR-12-2017-0540
52. Abdulaziz E, Kevin L. Perceived derived attributes of online customer reviews. Comput Hum Behav. 2016;56:306-319. doi:10.1016/j. chb.2015.11.051

53. Alireza G, Majid S, Mahdieh R. The impact of social capital and social interaction on customers' purchase intention, considering knowledge sharing in social commerce context. J Innov Knowl. 2019;10(8):231-237. doi:10.1016/j.jik.2019.08.004

54. Zhao Y. Measuring the social capital of laid-off Chinese workers. Curr Sociol. 2002;50(4):555-571. doi:10.1177/ 0011392102050004005

55. Chang HH, Fu CS, Jain HT. Modifying UTAUT and innovation diffusion theory to reveal online shopping behavior: familiarity and perceived risk as mediators. Inf Dev. 2016;32(5):1757-1773. doi: $10.1177 / 0266666915623317$

56. Choi CJ. User familiarity and satisfaction with food delivery mobile apps. Sage Open. 2020;10(4):1-10. doi:10.1177/2158244020970563

57. Tolstedt BE, Stokes JP. Relation of verbal, affective, and physical intimacy to marital satisfaction. J Couns Psychol. 1983;30:573-580. doi:10.1037/0022-0167.30.4.573

58. Lowenthal MF, Haven C. Interaction and adaptation: intimacy as a critical variable. Am Sociol Rev. 1968;33:20-30. doi:10.2307/ 2092237

59. Liang TP, Ho YT, Li YW, Turban E. What drives social commerce: the role of social support and relationship quality. Int $J$ Electron Commer. 2011;1616:69-90. doi:10.2753/JEC1086-4415160204

60. Bronner F, Hoog RD. Consumer-generated versus marketer-generated websites in consumer decision making. Int J Mark Res. 2010;52(2):231-248. doi:10.2501/ S1470785309201193

61. Lichtenthal JD, Tellefsen T. Toward a theory of business buyer-seller similarity. J Pers Selling Sales Manage. 2001;21(1):1-14.

62. Nelson P. Information and consumer behavior. J Polit Econ. 1970;78 (2):311-329. doi:10.1086/259630

63. Peterson RA, Balasubramanian S, Bronnenberg BJ. Exploring the implications of the internet for consumer marketing. J Acad Mark Sci. 1997;24(5):329-346. doi:10.1177/0092070397254005

64. Jimenez FR, Mendoza NA. Too popular to ignore: the influence of online reviews on purchase intentions of search and experience products. J Interact Mark. 2013;27(3):226-235. doi:10.1016/j. intmar.2013.04.004

65. Lu LC, Chang WP, Chang HH. Consumer attitudes toward blogger's sponsored recommendations and purchase intention: the effect of sponsorship type, product type, and brand awareness. Comput Hum Behav. 2014;34:258-266. doi:10.1016/j.chb.2014.02.007

66. Huang P, Lurie NH, Mitra S. Searching for experience on the web: an empirical examination of consumer behavior for search and experience goods. J Mark. 2009;73(2):55-69. doi:10.1509/jmkg.73.2.55

67. Kim K, Lee S, Choi YK. Image proximity in advertising appeals: spatial distance and product types. J Bus Res. 2019;99:490-497. doi:10.1016/j.jbusres.2017.08.031

68. Mudambi SM, Schuff D. What makes a helpful online review? A study of customer reviews on Amazon. Commer MIS Q. 2010;34 (1):185-200. doi:10.2307/20721420

69. Zafar AU, Qiu JN, Li Y, Wang JG, Shahzad M. The impact of social media celebrities' posts and contextual interactions on impulse buying in social commerce. Comput Hum Behav. 2021. 115. doi:10.1016/ j.chb.2019.106178

70. Xiang L, Zheng XB, Lee MKO, Zhao DT. Exploring consumers' impulse buying behavior on social commerce platform: the role of parasocial interaction. Int $J$ Inf Manage. 2016;3(36):333-347. doi:10.1016/j.ijinfomgt.2015.11.002

71. Cao YY, Li JJ, Qin XH, Hu BL. Examining the effect of overload on the mHealth application resistance behavior of elderly users: an SOR perspective. Int $J$ Environ Res Public Health. 2020;18(17):. doi:10.3390/ijerph17186658 
72. Zafar AU, Qiu JN, Shahzad M, Shen J, Bhutto TA, Irfan M. Impulse buying in social commerce: bundle offer, top reviews, and emotional intelligence. Asia Pac J Market Logist. 2020. doi:10.1108/APJML08-2019-0495

73. Hajli N. Social commerce constructs and consumer's intention to buy. Int $J$ Inf Manage. 2015;2(35):183-191. doi:10.1016/j. ijinfomgt.2014.12.005

74. Kozinets RV. The field behind the screen: using the method of netnography to research market-oriented virtual communities. J Consum Res. 2000;1(39):61-72.

75. Zhu B, Kowatthanakul S, Satanasavapak P. Generation Y consumer online repurchase intention in Bangkok based on stimulus-organismresponse (SOR) model. Int J Retail Distribut Manage. 2019;1 (48):53-69. doi:10.1108/IJRDM-04-2018-0071

76. Mehrabian A, Russell JA. An Approach to Environmental Psychology. Cambridge, MA: The MIT Press; 1974.

77. Sherman E, Mathur A, Smith RB. Store environment and consumer purchase behavior: mediating role of consumer emotions. Psychol Mark. 1997;4(14):361-378. doi:10.1002/(SICI)1520-6793(199707) $14: 4<361::$ AID-MAR4>3.0.CO;2-7

78. Podsakoff PM, MacKenzie SB, Lee JY, Podsakoff NP. Common method biases in behavioral research: a critical review of the literature and recommended remedies. $J$ Appl Psychol. 2003;88 (5):879-903. doi:10.1037/0021-9010.88.5.879

79. Rasch D. Statistics in Psychology Using R and SPSS. John Wiley \& Sons Incorporation Press; 2011.

80. Pei NN. Introduction to Educational Research Methods. Anhui Education Press; 1995.

81. Frenzen J, Nakamoto K. Structure, cooperation, and the flow of market information. J Consum Res. 1993;20:360-375. doi:10.1086/ 209355

82. Gilly MC, Graham JL, Wolfinbarger MF, Yale LJ. A dyadic study of interpersonal information search. J Acad Mark Sci. 1998;26 (2):83-100. doi:10.1177/0092070398262001

83. Park C, Lee TM. Antecedents of online reviews' usage and purchase influence: an empirical comparison of US and Korean consumers. $J$ Interact Mark. 2009;23(4):332-340. doi:10.1016/j.intmar.2009. 07.001

84. Zhang Y. Responses to humorous advertising: the moderating effect of need for cognition. $J$ Advert. 1996;25:15-32. doi:10.1080/ 00913367.1996 .10673493

85. Lowry PB, Gaskin J. Partial least squares (PLS) structural equation modeling (SEM) for building and testing behavioral causal theory: when to choose it and how to use it. IEEE Trans Prof Commun. 2014;57(2):123-146. doi:10.1109/TPC.2014.2312452
86. Williams LJ, Edwards JR, Vandenberg RJ. Recent advances in causal modeling methods for organizational and management research. $J$ Manage. 2003;29(6):903-936. doi:10.1016/S0149-2063(03)000 84-9

87. Nunnally J. Psychometric Theory. New York, NY: McGraw-Hill; 1978.

88. Hair JF, Hult GTM, Ringle CM, Sarstedt M. A primer on partial least squares structural equation modeling. In: Long Range Planning. 2nd ed. Sage Publication; 2017.

89. Latan H. PLS path modeling in hospitality and tourism research: the golden age and days of future past. In: Ali F, Rasoolimanesh MS, Cobanoglu C, editors. Application of Partial Least Squares Structural Equation Modeling (PLS-SEM) in Tourism and Hospitality Research. Bingley: Emerald; 2018.

90. Henseler J, Ringle CM, Sarstedt M. A new criterion for assessing discriminant validity in variance-based structural equation modeling. J Acad Mark Sci. 2015;43(1):115-135. doi:10.1007/s11747-0140403-8

91. Kline RB. Principles and Practice of Structural Equation Modeling. 2nd ed. New York: Fuilford; 2005.

92. Byrne BM. Structural Equation Modeling with AMOS (Multivariate Applications Series). Routledge; 2010.

93. Bentler RA. Effectiveness of directional microphones and noise reduction schemes in hearing aids: a systematic review of the evidence. J Am Acad Audiol. 2005;16(7):473-484. doi:10.3766/ jaaa.16.7.7

94. Chan W, Yung YF, Bentler PM. Tests of independence for ordinal data using bootstrap. Educ Psychol Meas. 1998;58(2):221-240. doi:10.1177/0013164498058002006

95. West R, Stafford DA, Farrow A, Jacobs A. Occupational and environmental exposures and myelodysplasia: a case-control study. Leuk Res. 1995;19:127-139. doi:10.1016/0145-2126(94)00141-V

96. Enders CK. Applying the Bollen-Stine Bootstrap for goodness-of-fit measures to structural equation models with missing data. Multivariate Behav Res. 2002;37(3):359-377. doi:10.1207/ S15327906MBR3703_3

97. Preacher KJ, Hayes AF. Asymptotic and resampling strategies for assessing and comparing indirect effects in multiple mediator models. Behav Res Method. 2008;40(3):879-891. doi:10.3758/BRM.40.3.879

98. Wang CJ, Tsai HT, Tsai MT. Linking transformational leadership and employee creativity in the hospitality industry: the influences of creative role identity, creative self-efficacy, and job complexity. Tourism Manage. 2014;(40):79-89. doi:10.1016/j.tourman.2013. 05.008
Psychology Research and Behavior Management

\section{Publish your work in this journal}

Psychology Research and Behavior Management is an international, peer-reviewed, open access journal focusing on the science of psychology and its application in behavior management to develop improved outcomes in the clinical, educational, sports and business arenas. Specific topics covered in the journal include: Neuroscience, memory and decision making; Behavior modification and management; Clinica applications; Business and sports performance management; Social and developmental studies; Animal studies. The manuscript management system is completely online and includes a very quick and fair peer-review system, which is all easy to use. Visit http://www. dovepress.com/testimonials.php to read real quotes from published authors. 